\title{
Lesões orofaríngeas e neurológicas em ovinos associadas ao uso de pistolas dosificadoras ${ }^{1}$
}

\author{
Fabiano J.F. de Sant'Ana2*, Edismair C. Garcia ${ }^{3}$, Rogério E. Rabelo ${ }^{4}$, Yara L. da \\ Costa $^{5}$, Ana L. Schild ${ }^{6}$ e Franklin Riet-Correa ${ }^{7}$
}

\begin{abstract}
Sant'Ana F.J.F., Garcia E.C., Rabelo R.E., Costa Y.L., Schild A.L. \& Riet-Correa F. 2007. [Oropharyngeal and neurologic lesions in sheep associated with the use of drenching guns.] Lesões orofaríngeas e neurológicas em ovinos associadas ao uso de pistolas dosificadoras. Pesquisa Veterinária Brasileira 27(7):282-286. Laboratório de Patologia Veterinária, Universidade Federal de Goiás, Campus Jataí, 75800-000 Jataí, GO, Brazil. E-mail: santanafjf@yahoo.com

Six outbreaks of oropharyngeal lesions caused by drenching guns in sheep are reported. In 2 outbreaks in Rio Grande do Sul the morbidity was $6.25 \%$ and $15 \%$, and the lesions observed after antihelmintic treatment in adult sheep were characterized by a fistula extending from mouth to skin of the face. All sheep died or were euthanatized after continuous weight loss for up to 8 months. Another outbreak in the same State affected 26 out of 360 adult sheep after being dosed with molasses, causing lesions in the oral mucosa followed by malignant edema of the oral and subcutaneous tissues. All sheep died within 10 days after treatment. Another case observed in Rio Grande do Sul affected one out of 88 adult ewes. The animal died with hemorrhages from the nose and mouth 8 days after antihelmintic treatment. At necropsy an ulcerated lesion covered by a clot of fibrine was found in the oral mucosa. The lesion had a fistulated tract with purulent exudate extending through the soft tissues in direction to the right eye. Two outbreaks occurred in the State of Goiás 16-20 days after antihelmintic treatment in 5-9 months old lambs. Morbidity was $11.43 \%$ and $15.62 \%$ and fatality rate was $7.14 \%$ and $9.38 \%$. Main clinical signs were nervous signs caused by abscesses with a diameter of $0.5-3 \mathrm{~cm}$, containing purulent exudates in the oropharynx, soft palate and adjacent muscles extending to the meninges through the atlantoaxial joint. Not-purulent meningitis was observed histologically. The need to use proper drenching guns and pay attention during dosing to avoid lesions of the oropharynx is pointed out.
\end{abstract}

INDEX TERMS: Oropharyngeal abscess, neurologic alterations, drenching guns, sheep.

RESUMO.- Descrevem-se 6 surtos de lesões orofaríngeas em ovinos causadas por pistolas para administração oral de anti-

\footnotetext{
${ }^{1}$ Recebido em 19 de dezembro de 2006.

Aceito para publicação em 3 de janeiro de 2007.

${ }^{2}$ Laboratório de Patologia Veterinária (LPV), Universidade Federal de Goiás (UFG), Campus Jataí (CAJ), BR 364 Km 192, Setor Parque Industrial, Jataí, GO 75800-000, Brasil. *Autor para correspondência: santanafif@yahoo.com

3 Graduando em Medicina Veterinária, Monitor de Anatomia Patológica Animal, LPV, UFG-CAJ, Jataí, GO 75800-000.

${ }^{4}$ Ambulatório Veterinário, UFG-CAJ, Jataí, GO 75800-000.

${ }^{5}$ Graduanda em Medicina Veterinária, Bolsista de Extensão (PROBEC/UFG), LPV, UFG-CAJ, Jataí, GO 75800-000.

${ }^{6}$ Laboratório Regional de Diagnóstico, Faculdade de Veterinária, Universidade Federal de Pelotas, 96010-900 Pelotas, Rio Grande do Sul.

${ }^{7}$ Hospital Veterinário, CSTR, Universidade Federal de Campina Grande, 58700-000 Patos, Paraíba.
}

helmínticos. Em 2 surtos ocorridos no Rio Grande do Sul, com morbidade de $6,25 \%$ e $15 \%$ as lesões ocorreram em ovinos de diferentes idades após o tratamento anti-helmíntico. Caracterizaram-se por fístulas que se estendiam através dos tecidos moles desde a boca até a pele da face. Todos os animais morreram ou foram eutanasiados após perda contínua de peso após um curso clínico de até 8 meses. Outro surto nesse mesmo Estado, com uma morbidade de 7,22\% caracterizou-se por lesões de edema maligno originadas por traumatismos causados na mucosa oral durante a administração de melaço. Todos os animais morreram em 10 dias após o tratamento. No quarto surto observado no Rio Grande do Sul, houve uma ovelha adulta afetada, de um total de 88 , que apresentou severa hemorragia pelo nariz e pela boca 8 dias após ter sido tratada oralmente com anti-helmíntico. Na necropsia apresentava aumento de volume pela face interna da mandíbula 
do lado direito e bochecha cuja mucosa estava ulcerada, com um coágulo e secreção purulenta com formação de fístula que se estendia pelos tecidos moles em direção ao globo ocular. Dois surtos ocorreram no Estado de Goiás, 16-20 dias após o tratamento oral com anti-helmínticos em cordeiros de 5-9 meses de idade. A morbidade foi de $11,43 \%$ e $15,62 \%$ e mortalidade de $7,14 \%$ e $9,38 \%$. Os animais apresentaram, principalmente, sinais nervosos, causados por abscessos que variavam de $0,5-3 \mathrm{~cm}$ de diâmetro, contendo exsudato purulento amarelado no seu interior, localizados na orofaringe, palato mole e musculatura esquelética adjacente estendendo-se às meninges através da articulação atlanto-occipital. Meningite nãopurulenta foi observada histologicamente. Alerta-se para a necessidade de utilização de pistolas em boas condições e prestar atenção no momento do tratamento oral com antihelmínticos para evitar ferimentos na orofaringe de ovinos.

TERMOS DE INDEXAÇÃO: Abscessos orofaríngeos, alterações neurológicas, tratamento oral com anti-helmínticos, ovinos.

\section{INTRODUÇÃO}

Em ovinos, uma das principais formas de tratamento antihelmíntico consiste na aplicação de drogas, via oral, utilizando as denominadas pistolas dosificadoras. Quando essa técnica não é realizada com os devidos cuidados, lesões traumáticas penetrantes na boca, faringe, laringe e tecidos circunvizinhos podem ocorrer (López 1998). Nesses casos pode-se observar edema, inflamação local, perfuração da parede pósterodorsal da faringe, abscessos e celulite (López 1998, Radostits et al. 2002).

Este trabalho tem por objetivo descrever 6 surtos de lesões orofaríngeas em ovinos que ocorreram em consequiência da administração oral de anti-helmínticos ou melaço com pistolas dosificadoras. Quatro surtos ocorreram no Rio Grande do Sul e dois no sudoeste de Goiás. Estes últimos apresentaram comprometimento neurológico secundário às alterações orofaríngeas.

\section{MATERIAL E MÉTODOS}

Os 4 surtos relatados no Rio Grande do Sul ocorreram nos anos de 1978-2006 e os dados relativos à epidemiologia e aos sinais clínicos foram obtidos nos protocolos de necropsias do Laboratório Regional de Diagnóstico da Faculdade de Veterinária da Universidade Federal de Pelotas. Algumas informações de alguns desses surtos não estavam disponíveis nos protocolos. Dois ovinos do Surto 2 e um de cada um dos surtos restantes foram enviados mortos ao laboratório e necropsiados. Fragmentos dos diversos órgãos foram fixados em formalina $10 \%$, cortados com $5 \mu \mathrm{m}$ de espessura e corados com hematoxilina-eosina (HE). Material das lesões observadas no ovino do Surto 3 foi coletado para realização de culturas bacterianas aeróbicas e anaeróbicas.

Os 2 surtos observados no Estado de Goiás ocorreram em rebanhos de criação extensiva (Propriedade A e B). Quatro ovinos da Propriedade A e três da Propriedade B foram enviados vivos (dois da A e um da B) e mortos (dois da A e dois da B) para exame clínico e/ou necropsia na Universidade Federal de Goiás, Campus Jataí. Nos animais que chegaram vivos, após exame físico geral e prévia identificação, foi realizado exame neurológico específico. O histórico clínico foi obtido com os proprietários e/ou tratadores. Os animais que morreram naturalmente ou que foram eutanasiados in extremis (devido ao prognóstico desfavorável) foram submetidos à necropsia, sendo coletados fragmentos de vários órgãos, os quais foram fixados em formol tamponado a $10 \%$, processados rotineiramente para histopatologia e corados por HE. Amostras de fígado e de soro foram coletadas de três animais para dosagem de cobre. Foram realizados hemogramas em dois ovinos da Propriedade A e em um da Propriedade B.

\section{RESULTADOS}

\section{Surtos observados no Rio Grande do Sul}

No Surto 1, ocorrido no município de Piratiní, em agosto de 1979 , foram afetados $5(6,25 \%)$ ovinos de um rebanho de 80 , de 2 anos de idade. No Surto 2, no município de Herval, em 1986 foram afetados 30 (15\%) ovelhas adultas, de um rebanho de 200. Nestes dois surtos os sinais clínicos, observados 15-20 dias após o tratamento oral com anti-helmínticos, caracterizaram-se por emagrecimento progressivo e morte, com presença de uma fístula com conteúdo purulento misturado com alimento, localizada na pele lateralmente à mandíbula ou intermandibular (Fig.1). No Surto 2, as 30 mortes ocorreram de maio a dezembro. Na necropsia de dois ovinos, foi

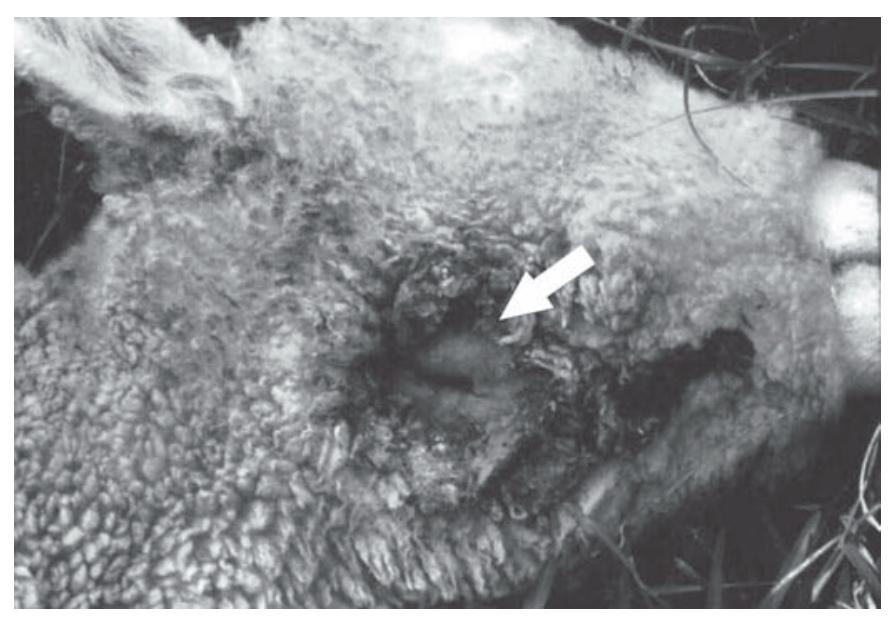

Fig.1. Fístula na região mandibular (seta) que comunica com a cavidade oral, em ovino do Surto 2.

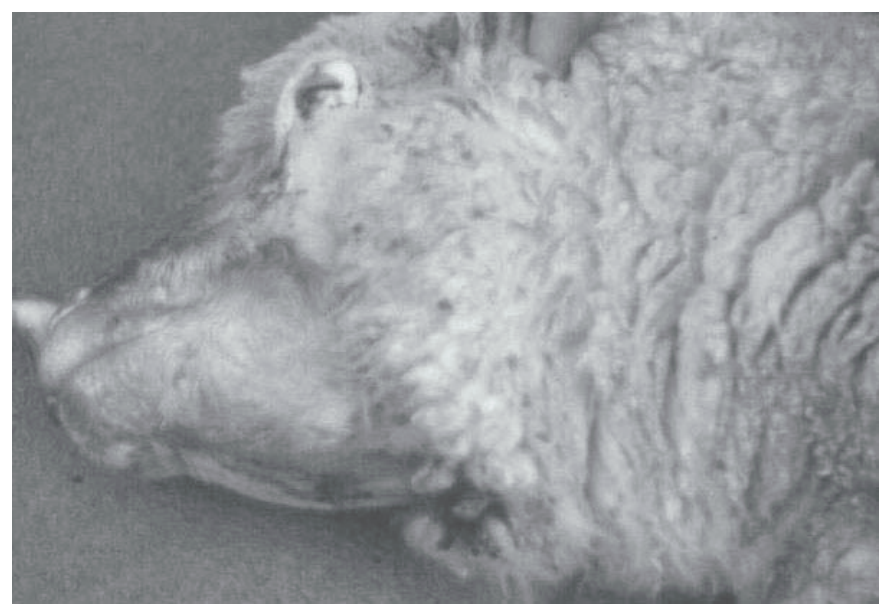

Fig.2. Edema submandibular em ovino do Surto 3. 

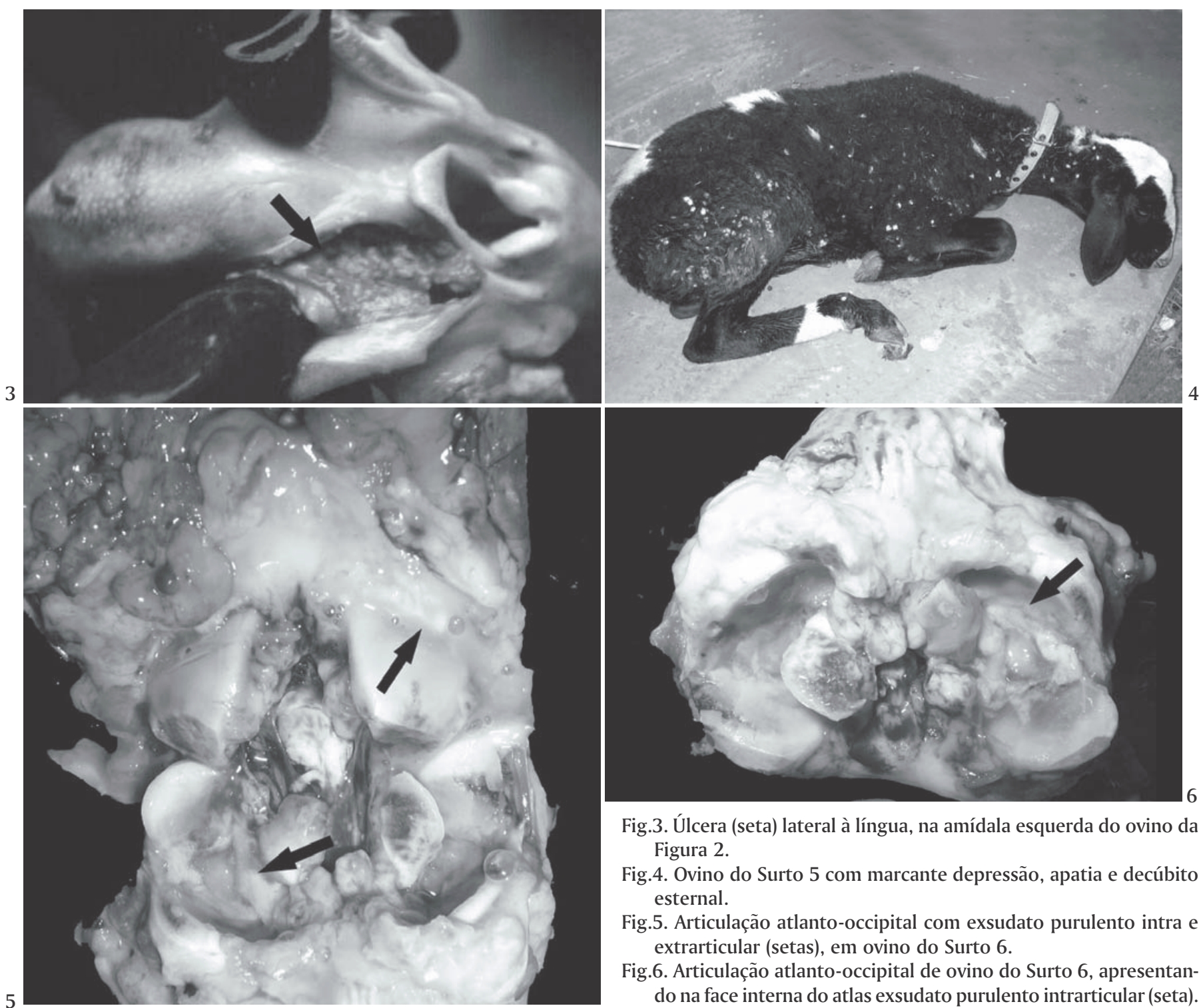

Fig.3. Úlcera (seta) lateral à língua, na amídala esquerda do ovino da Figura 2.

Fig.4. Ovino do Surto 5 com marcante depressão, apatia e decúbito esternal.

Fig.5. Articulação atlanto-occipital com exsudato purulento intra e extrarticular (setas), em ovino do Surto 6.

Fig.6. Articulação atlanto-occipital de ovino do Surto 6, apresentando na face interna do atlas exsudato purulento intrarticular (seta).

observada lesão purulenta, situada, lateralmente à raiz da língua ou no vestíbulo, que se difundia em forma de fístula através dos tecidos moles até atingir a pele.

O Surto 3, que ocorreu em 1981 no município de Piratiní, afetou $26(7,2 \%)$ ovinos de um rebanho de 360 ovelhas adultas. Nesses casos a lesão causada pelo aparelho de dosificar caraterizou-se por edema maligno nos tecidos intermandibulares. Aos animais tinha sido administrado melaço diluído a $10 \%$ com água. Apresentaram marcada apatia, emagrecimento e severo edema submandibular (Fig.2), morrendo em até 10 dias após a dosificação. Na necropsia observaram-se lesões ulcerativas localizadas lateralmente à raiz da língua e na faringe (Fig.3). Os tecidos inter-mandibulares apresentavam lesões de edema maligno, caracterizadas por edema de cor marrom amarelada e odor fétido. Nas culturas realizadas do material obtido das lesões foi isolada flora polimicrobiana incluindo Clostridium spp.

Um último caso (Surto 4) de lesões associadas à utilização de pistolas dosificadoras ocorreu no município de Capão do Leão em maio de $2006 \mathrm{em}$ uma ovelha, de um rebanho de 88 ovelhas adultas, a qual apresentou severa hemorragia pelo nariz e pela boca 8 dias após ter sido tratada oralmente com anti-helmíntico. Na necropsia apresentava aumento de volume da face interna da mandíbula e da bochecha do lado direito. A mucosa da bochecha estava ulcerada contendo um coágulo e secreção purulenta com formação de fístula que se estendia pelos tecidos moles em direção ao globo ocular.

Nos diversos órgãos coletados de todos os animais necropsiados para estudo histológico não foram observadas lesões histológicas significativas.

\section{Surtos no Estado de Goiás}

Os 2 surtos observados no Estado de Goiás ocorreram durante os meses de abril e maio de 2006 em dois rebanhos pertencentes às Propriedades A e B, ambas localizadas no município de Jataí, sudoeste de Goiás. 
Na Propriedade A, de um total de 280 ovinos sem raça definida (SRD), que tinham entre 4 meses e 2 anos de idade, 32 adoeceram e 20 morreram (morbidade 11,43\%, mortalidade $7,14 \%)$. Na Propriedade $B$, de um rebanho de 96 animais (836 meses) SRD e Santa Inês, 15 adoeceram e nove morreram (morbidade 15,62\%, mortalidade 9,38\%). Nas duas propriedades, os animais enfermos tinham entre 5 e 9 meses e os sinais clínicos da enfermidade surgiram, em média, 16-20 dias após o tratamento oral de todos os animais do rebanho com antihelmínticos utilizando pistola dosificadora. Os tratamentos anti-helmínticos estavam sendo realizados a cada 30 (Propriedade A) ou 60 dias (Propriedade B). Na Propriedade B, era prática comum o fornecimento de sal mineral de origem desconhecida formulada pelo proprietário e na Propriedade A não havia fornecimento de mineralização suplementar.

Os sinais clínicos manifestados pelos animais nas duas propriedades eram semelhantes e consistiam de apatia, letargia, prostração, decúbito esternal, tremores musculares especialmente na região cervical e na altura da escápula, paralisia espástica dos membros torácicos e pélvicos, bruxismo (em alguns animais), queda do pescoço, apesar do apetite preservado (Fig.4). Não foram detectadas alterações significativas associadas a déficits de nervos cranianos.

Macroscopicamente, observou-se, em todos os animais necropsiados, abscessos que variavam de $0,5-3 \mathrm{~cm}$ de diâmetro, contendo exsudato purulento amarelado no seu interior, que estavam localizados na orofaringe, palato mole e musculatura esquelética adjacente. No momento de desarticular a cabeça do pescoço, via articulação atlanto-occipital, para retirada posterior do encéfalo, foi notado em três dos sete ovinos necropsiados que a inflamação purulenta, ora descrita, estendia-se no sentido dessa articulação inflamando todos os músculos cervicais vizinhos, inclusive com exsudação no espaço articular (Fig.5 e 6). Além disso, evidenciou-se hiperemia moderada do encéfalo e fígado com coloração discretamente amarelada e com aumento do padrão lobular, sugerindo processo degenerativo.

No exame histológico do encéfalo, foi observada leptomeningite não-supurada discreta a moderada em cortes do córtex

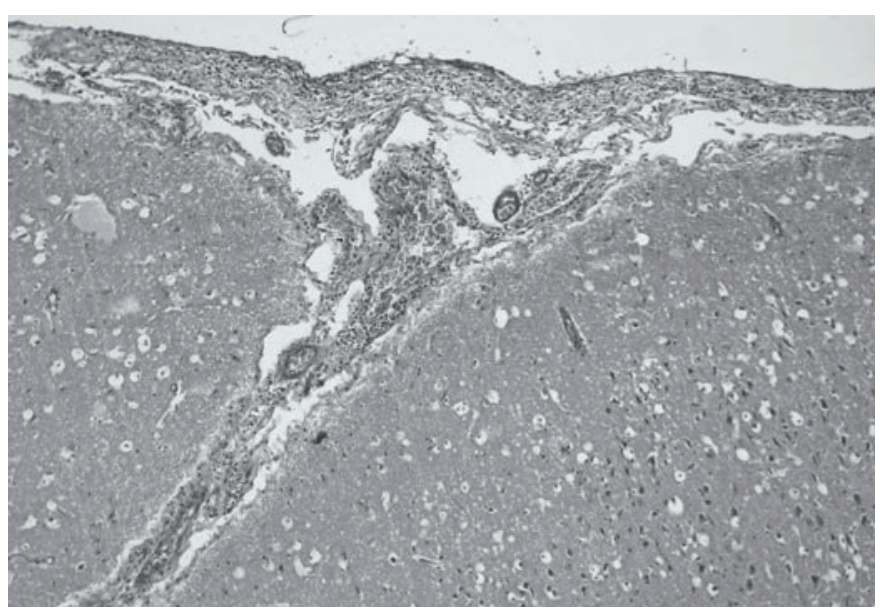

Fig.7. Leptomeningite não-purulenta no córtex occipital, em ovino do Surto 5. HE, obj.10. occipital associada à hiperemia de arteríolas (Fig.7). Nas demais regiões do encéfalo, notaram-se apenas focos discretos de gliose e tumefação de algumas células endoteliais. Não foram detectadas alterações significativas na medula espinhal.

Nenhuma alteração foi detectada nos exames hematológicos realizados. As concentrações de cobre no soro $(X=81,2 \mathrm{ppm})$ e no fígado $(X=72,4 \mathrm{ppm})$ estavam dentro dos parâmetros considerados normais para a espécie.

\section{DISCUSSÃO}

Em 5 surtos descritos neste trabalho as lesões orofaríngeas foram associadas ao tratamento com anti-helmínticos utilizando aparelhos para administrar anti-helmínticos oralmente, denominados também como pistolas dosificadoras (Surtos 1, 2, 4, 5 e 6) ou após à administração de melaço (Surto 3), também, com pistola dosificadora. Esta associação é sugerida pelas lesões de provável origem traumáticas encontradas na boca e porque ocorreram num período de 15-20 dias após o tratamento nos Surtos 1, 2, 5 e 6 nos quais as lesões eram purulentas, ou ainda mais rápido, no Surto 3 no qual ocorreram lesões gangrenosas, e no Surto 4 no qual um caso individual apresentou sangramento pelas narinas e boca associados a uma lesão hemorrágica.

Apesar de todos os surtos terem aparentemente a mesma causa, traumatismos causados pelas pistolas dosificadoras, seguidos de um processo purulento, hemorrágico ou gangrenoso, resultaram em quatro formas clínicas diferentes. Nos Surtos 1 e 2 as lesões ocorreram na boca lateralmente à língua, instalando-se um processo purulento secundário que por gravidade se difunde através dos tecidos moles drenando na pele e causando uma fístula desde a cavidade oral, que por conter resíduos de alimentos não tinha possibilidade de curar espontaneamente. No Surto 3 o que ocorreu foi uma infecção das feridas causadas pelo aparelho de dosar por Clostridium spp. e outras bactérias que causaram lesões típicas de edema maligno. É provável que neste caso a contaminação tenha sido proveniente do melaço que foi administrado aos animais. No animal afetado no Surto 4 havia lesões hemorrágicas.

Nos Surtos 5 e 6, o que mais chamou a atenção foi o comprometimento secundário neurológico. Os aspectos clínicos e, principalmente, os anatomopatológicos observados, sugerem que as alterações neurológicas foram causadas por extensão do processo inflamatório supurado localizado na orofaringe e palato mole até a articulação atlanto-occipital migrando para o sistema nervoso central. Nestes surtos embora não tenha sido informado pelos proprietários e tratadores, é possível que a contenção inadequada associada ao estresse dos animais no momento do tratamento oral com anti-helmínticos tenha contribuído para as lesões traumáticas orofaríngeas, provavelmente causadas pela pistola dosificadora, uma vez que todos os animais das duas propriedades passaram pelo mesmo manejo antiparasitário. Ao contrário do que ocorreu nos Surtos 1 a 4 nos quais foram afetados ovinos de diversas idades, nos Surtos 5 e 6 foram afetados apenas animais jovens o que sugere que esta faixa etária 
está sob maior risco de desenvolver lesões que se estendam ao sistema nervoso.

Os resultados deste trabalho mostram que traumatismos causados na orofaringe por aparelhos para tratar ovinos oralmente podem causar quadros clínicos diferentes, dependendo, provavelmente do tipo de aparelho, do local da lesão e dos agentes que causem infecção. Rivero et al. (1989) descrevem outro tipo de alteração causada por pistolas dosificadoras caracterizada por lesões da faringe, que evoluem para abscessos ou flegmões retrofaríngeos e periesofágicos. Nesses casos, os ovinos apresentam 15-20 dias após terem sido tratados, marcada depressão e anorexia e, em alguns animais, detectase tumefação localizada, na maioria das vezes, na zona ventral do pescoço. Na necropsia observa-se coleção de pus, que se estende desde a região retrofaríngea até a entrada do peito, passando dorsalmente à traquéia e ao esôfago. Radostits et al. (2002) alertam para o fato de que lesões traumáticas na cavidade oral de ruminantes podem trazer sérias conseqüências, pois agentes oportunistas, principalmente bacterianos, podem aproveitar essa porta de entrada e migrarem para outros tecidos e sistemas causando alterações inflamatórias graves como ocorre na actinobacilose, actinomicose e listeriose.

O diagnóstico da enfermidade, com base no histórico e na localização e tipo de lesões observadas é relativamente fácil. No entanto, nos Surtos 5 e 6 , o quadro clínico era semelhante, em alguns aspectos, ao encontrado na deficiência de cobre, mas as dosagens desse mineral feitas com amostras de fígado e soro dos ovinos mostraram resultados dentro dos parâmetros normais para a espécie. Essa deficiência mineral foi incluída no diagnóstico diferencial também em função do histórico de falhas na mineralização do rebanho, nos dois criatórios. Ademais, não foram detectadas alterações histológicas, encefálicas ou medulares, compatíveis com deficiência de cobre, como degeneração da mielina (degeneração walleriana), degeneração neuronal, hipomielinogênese ou hidranencefalia, conforme descrito por outros autores (Tokarnia et al. 1966, Riet-Correa 2001, Riet-Correa et al. 2002).

Este trabalho mostra a necessidade de se prestar atenção no momento do tratamento oral com anti-helmínticos em ovinos para evitar ferimentos na orofaringe, constatando que a pistola dosificadora não tenha irregularidades ou áreas cortantes que possam ferir a orofaringe dos animais; imobilizando corretamente aos animais durante a administração de medicamentos via oral evitando ferimentos com a pistola de dosar em conseqüência de movimentos bruscos; e depositando o medicamento com a extremidade da pistola em cima da língua evitando alcançar a faringe do animal.

\section{REFERÊNCIAS}

López A. 1998. Sistema respiratório, p.132-193. In: Carlton W.W. \& McGavin M.D. (ed.), Patologia Veterinária Especial de Thomson. $2^{\underline{a}}$ ed. Artmed, Porto Alegre.

Radostits O.M., Gay C.C., Blood D.C. \& Hinchcliff K.W. 2002. Clínica Veterinária: um tratado de doenças dos bovinos, ovinos, suínos, caprinos e eqüinos. $9^{a}$ ed., Guanabara Koogan, Rio de Janeiro. 1737p.

Riet-Correa F. 2001. Deficiência de cobre, p.312-320. In: Riet-Correa F., Schild A.L., Méndez M.C. \& Lemos R.A.A. (ed.), Doenças de Ruminantes e Eqüinos. $2^{a}$ ed. Vol. 2. Varela, São Paulo.

Riet-Correa F., Riet-Correa G. \& Schild A.L. 2002. Importância do exame clínico para o diagnóstico das enfermidades do sistema nervoso em ruminantes e equí́deos. Pesq. Vet. Bras. 22(4):161-168.

Rivero R., Quintana S., Féola R. \& Haedo F. 1989. Principales enfermedades diagnosticadas en el area de influência del Laboratorio de Diagnóstico Regional Noroeste del CIVET Miguel C. Rubino. 17ª Jornada Uruguaya de Buiatría, Seção I, p.1-73.

Tokarnia C.H., Döbereiner J., Canella C.F.C. \& Guimarães G.A. 1966. Ataxia enzoótica em cordeiros no Piauí. Pesq. Agropec. Bras. 1:375-382. 